\title{
ESTUDO EXPLORATÓRIO DAS TERRITORIALIDADES BASEADAS NAS TRANSFORMAÇÕES DA AGRICULTURA FAMILIAR SOBRE A LINHA ALDA - VIADUTOS/RS
}

\author{
EXPLORATORY STUDY OF TERRITORIALITIES BASED ON FAMILY FARMING \\ TRANSFORMATIONS ON THE ALDA LINE - VIADUTOS/RS
}

\section{ESTUDIO EXPLORATORIO DE LAS TERRITORIALIDADES BASADO EN LAS TRANSFORMACIONES DE LA AGRICULTURA FAMILIAR EN LA LÍNEA ALDA- VIADUTOS/RS}

\author{
Izabela Fagundes ${ }^{1}$ \\ https://orcid.org/0000-0002-9999-6893 \\ Marcio Freitas Eduardo ${ }^{2}$ \\ https://orcid.org/0000-0003-2641-1636
}

Submissão: 02/07/2020 / Aceito: 08/12/2020 / Publicado: 30/06/2021.

\begin{abstract}
Resumo
Este artigo visa, em nível exploratório, compreender como as dinâmicas territoriais se apresentam sobre a Linha Alda-Viadutos/RS. Para tanto, delimitamos três momentos de análise: o primeiro referente ao contexto histórico de construção de identidades e territorialidades dos estabelecimentos rurais da agricultura familiar localizados na Linha Alda; na sequência, apresentamos elementos sobre as mudanças resultantes dos processos de modernização da base técnica da produção, intensificadas a partir de 1970; e, por fim, um terceiro momento em que é realizada uma análise da configuração das dinâmicas territoriais recentes, marcadas pela paisagem da especialização produtiva e pelo declínio populacional e das territorialidades comunitárias estabelecidas outrora. A metodologia utilizada foi a pesquisa participante, trabalho de campo e a pesquisa bibliográfica documental. Desta forma, apresentamos um panorama geral sobre as dinâmicas territoriais da Linha Alda, que incluem os nanoterritórios das unidades de produção da agricultura familiar e as territorialidades na escala da localidade rural. Por meio deste estudo, foi possível apreender as circunstâncias que forjaram os atuais vínculos sociais difusos dos moradores da Linha Alda. Por conta disso, o uso da figura de linguagem: "será o fim da linha"?

Palavras-chave: Agricultura Familiar. Dinâmica territorial. Linha Alda. Territorialidades.
\end{abstract}

\begin{abstract}
This article aims at an exploratory level to understand how the territorial dynamics are presented on the Alda Line-Viadutos / RS. To this end, three moments of analysis will be delimited, the first referring to the historical context of the construction of identities and territorialities of rural properties located in the Alda Line, following, presenting elements and questions about the modernization of the means of production from 1970 and the stagnation. rural properties regarding the mechanisms of agricultural production and a third moment in which an analysis of the
\end{abstract}

\footnotetext{
1 Especialista em Sociedade, Ambiente e Desenvolvimento, UERGS, 2019.Email: izabela_fagundes@ @otmail.com. 2 Doutor em Geografia, professor Adjunto III do curso de Geografia - Licenciatura na Universidade Federal da Fronteira Sul (UFFS - Campus de Erechim/RS). Email: marcioeduardo@uffs.edu.br
} 
configuration of recent territorial dynamics is performed. For this research, the methodology used was participant observation, fieldwork and documentary bibliographic research. This study comprises an exploratory research that aimed to present an overview of the territorial dynamics of the Alda Line that include the nanoterritories of rural units, based on family farming. Through the observation and understanding of the territorial dynamics, it was possible to understand and realize that the social ties are diffuse and the population of the Alda Line is mostly elderly, as a possibility of reframing this locality, proposes to rethink the use of land through agroecological production or Agroforestry Systems - SAFS..

Keywords:Alda line. Family farming. Territorial dynamics. Territorialities.

\section{Resumen}

Este artículo tiene como objetivo un nivel exploratorio para comprender cómo se presentan las dinámicas territoriales en la línea Alda-Viadutos / RS. Con este fin, se delimitarán tres momentos de análisis, el primero se refiere al contexto histórico de la construcción de identidades y territorialidades de propiedades rurales ubicadas en la Línea Alda, a continuación, presentando elementos y preguntas sobre la modernización de los medios de producción a partir de 1970 y el estancamiento. propiedades rurales con respecto a los mecanismos de producción agrícola y un tercer momento en el que se realiza un análisis de la configuración de la dinámica territorial reciente. Para esta investigación, la metodología utilizada fue la observación participante, el trabajo de campo y la investigación bibliográfica documental. Este estudio comprende una investigación exploratoria que tuvo como objetivo presentar una visión general de la dinámica territorial de la Línea Alda que incluye los nanoterritorios de las unidades rurales, basados en la agricultura familiar. A través de la observación y comprensión de la dinámica territorial, fue posible comprender y darse cuenta de que los lazos sociales son difusos y que la población de la Línea Alda es mayormente mayor, como una posibilidad de replantear esta localidad, propone repensar el uso de la tierra a través de la producción agroecológica o Sistemas Agroforestales SAFS.

Palabras-clave: Agricultura Familiar. Dinámica territorial. Línea Alda. Territorialidade.

\section{INTRODUÇÃO}

O presente estudo está assentado nos resultados de uma pesquisa monográfica desenvolvida em âmbito do curso de especialização em Sociedade, Ambiente e Desenvolvimento, oferecido pela Universidade Estadual do Rio Grande do Sul (UERGS - núcleo Erechim/RS) entre 2018 e 2019. O curso, de caráter interdisciplinar, abordou temas referentes às questões sociais, ambientais, econômicas, espaciais e culturais. As reflexões realizadas nas disciplinas permitiram pensar e problematizar as relações sociedade - natureza e o (des)envolvimento social e territorial brasileiro, especialmente do Sul do Brasil. Nesta perspectiva, este artigo visa, em nível exploratório, compreender como as dinâmicas territoriais se apresentam sobre a Linha Alda Viadutos/RS (mapa 01), sobre um recorte temporal divido em 03 períodos de análise. 
$\mathrm{O}$ intuito da pesquisa foi verificar como as territorialidades se remodelaram e as dinâmicas territoriais da Linha Alda foram sendo reestruturadas ao longo de um século. Considerase desta forma, entre outros aspectos, o predomínio da agricultura pautado na produção de commodities (soja, milho e trigo) e na produção de proteína animal (suínos, aves e leite), integrada aos complexos agroindustriais.

\section{A SUCESSÃO DAS DINÂMICAS TERRITORIAIS DA LINHA ALDA, ViAdUTOS/RS}

Como recurso de pesquisa e de exposição, optamos por sistematizar as transformações das dinâmicas territoriais na Linha Alda, dividindo-as em três momentos distintos:

a) Primeiro, compreendendo o início do século XX até a década de 1960, caracterizado pela reterritorialização das famílias (ou dos descendentes) de origem étnica italiana, alemã e polonesa (sobretudo) - colonizadores da região Norte do Rio Grande do Sul, das áreas chamadas de "colônias novas" - até a afirmação das territorialidades dessa agricultura diversificada e pequeno-mercantil (Piran, 2001) da "frente pioneira e de expansão" (Waibel, 1955), exercida pelos sujeitos conhecidos como "colonos";

b) Posteriormente, com recorte temporal analítico entre as décadas de 1960 e 1990, enfocamos as mudanças processadas nas unidades familiares e da "comunidade"/localidade rural Linha Alda, deflagradas com o advento da modernização da agricultura. Processo este contraditório, que expressou, concomitantemente, importantes transformações econômicas como a ampliação da produção/produtividade por unidade de área e a especialização econômico territorial, mas também a estagnação, as crises e as migrações compulsórias por parte de um efetivo considerável de agricultores familiares e, como consequência da exacerbação do ímpeto competitivo e individualista, as repercussões nas territorialidades comunitárias precedentes.

c) Por fim, analisamos as territorialidades da Linha Alda no período mais recente, denotando o esvaziamento populacional, a "monopolização do território pelo capital" (Oliveira,2012) representado pela heteronomia dos agricultores familiares diante da expansão da monocultura e da integração agroindustrial convencionais. Nesta esteira, inscreve-se também a erosão dos vínculos de comunidade que anteriormente constituíam o cimento social da Linha Alda. 
A pesquisa não visa produzir uma análise exaustiva acerca do objeto em questão, mas apontar, com base em um estudo de caso, os fenômenos recorrentes nas áreas de agricultura familiar do Sul do Brasil. São eles: a contínua diminuição da população rural em face da inviabilidade econômica de reprodução das famílias sob a égide da agricultura convencional; o envelhecimento e a falta de perspectiva para a sucessão na agricultura familiar; e o enfraquecimento ou rompimento das territorialidades comunitárias (ou da "comunidade", como se referem os próprios sujeitos da pesquisa).

Considerando ainda a pouca bibliografia disponível sobre o tema e o nosso recorte de pesquisa, valemo-nos da metodologia da pesquisa exploratória que, de acordo com Gil (1987, p.44), “[...] pode ser entendida enquanto uma possibilidade de desenvolver, esclarecer, e modificar conceitos com o intuito de propor questões que poderão ser utilizadas para estudos posteriores".

Nesta perspectiva, para fazer a análise da face vivida e das territorialidades da Linha Alda, baseou-se em Marconi e Lakatos (2010), que abordam a pesquisa documental primária para compreender a análise de documentos públicos, recortes de jornais e fotografias tanto dos arquivos pessoais das famílias quanto registros fotográficos da autora, imagens de satélite e mapas para situar a área de estudo. Outra ferramenta de análise foi a pesquisa bibliográfica para apoio teórico das informações coletadas através da pesquisa de campo, realizada por meio do deslocamento até as residências dos agricultores e agricultoras familiares.

A pesquisa participante contou com o trabalho de campo para realizar a coleta de informações sobre a configuração inicial das propriedades familiares e compreender o contexto social, econômico e cultural que envolve estes sujeitos. No total, oito pessoas de sete famílias participaram desta pesquisa, contribuindo por meio de relatos de vivências, fotografias e memórias do tempo vivido na localidade.

O limite do público envolvido na pesquisa ocorreu em função da exaustão das informações, dado que algumas informações se repetiram na fala dos 6 entrevistados que pertencem a faixa etária acima dos 85 anos, assim como nos relatos de outras 8 pessoas com idades entre 53 e 68 anos.

Conforme dados do Instituto Brasileiro de Geografia e Estatística (IBGE Cidades) sobre o Censo Demográfico de 2010, a população total do município de Viadutos correspondia a 5.311. Destas pessoas, $2668(50,2 \%)$ vivem no espaço rural, $901(33,7 \%)$ pessoas corresponde a quantidade de jovens até 29 anos. Estes dados demonstram que o espaço rural de Viadutos é 
constituído majoritariamente por pessoas adultas ou idosas, deste total, o quadro populacional referente à Linha Alda - corresponde a 20 pessoas entre jovens, adultos e idosos.

A partir destes dados, questiona-se porque apesar dos indicadores populacionais demonstrarem um número expressivo de jovens vivendo no campo no município de Viadutos/Rs, na localidade da Linha Alda, ocorre um processo inverso, ou seja, um esvaziamento referente a saída tanto de jovens quanto de famílias inteiras. Este processo é recorrente desde o início da ocupação da área de estudo (1910) como será comprovado nos relatos dos moradores na sequência do texto.

\section{Mapa 1 - Localização da Linha Alda no município de Viadutos Estado do Rio Grande do} Sul.

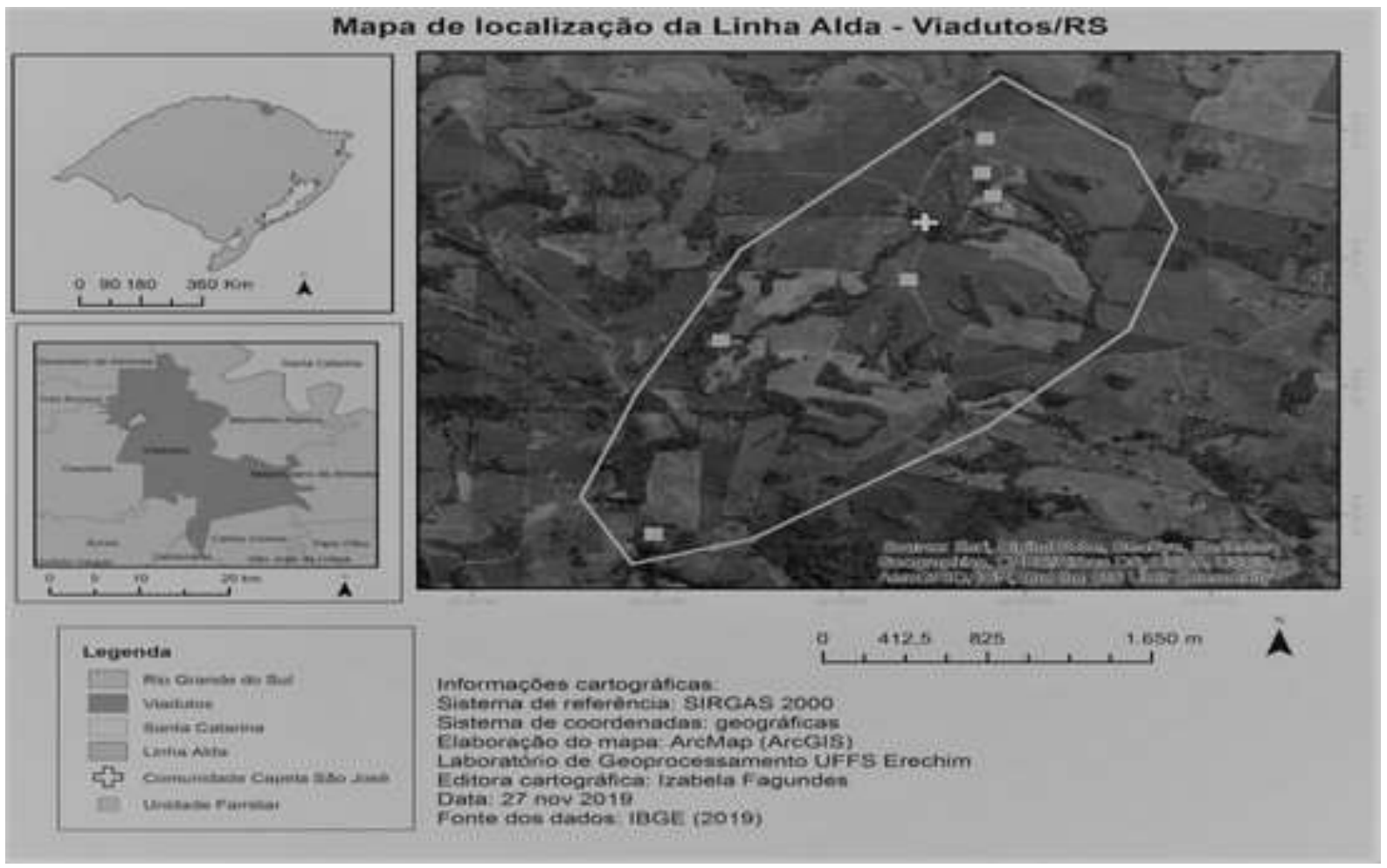

Fonte: Fagundes(2019).

A Linha Alda compreende, segundo relato de um dos agricultores (89 anos), uma porção territorial equivalente a duas colônias ${ }^{3}$ de terra. A Linha Alda, inicialmente enquanto um território, expressava o poder e dominação do Estado enquanto agente regulador dos territórios.

Após o momento da colonização desta porção territorial, a Linha Alda perdeu sua característica enquanto território. Neste momento (2019), compreende a soma de 5 propriedades

\footnotetext{
${ }^{3}$ Duas colônias de terras correspondem á $50000 \mathrm{~m}^{2}$.
} 
baseadas na agricultura familiar, que expressam as relações sociais entre as famílias, ou seja, a face vivida do local.

Nesta perspectiva, Claude Raffestin (1993, p.159) define a territorialidade como um valor particular, que reflete a multidimensionalidade do "vivido" territorial pelos membros de um coletivo, no caso, a Linha Alda. O autor destaca que "a territorialidade se apresenta de forma consubstancial a todas as relações e representa a 'face vivida' da 'face agida,' do poder.". (RAFFESTIN, 1993, p.162).

\section{ELEMENTOS DA FORMAÇÃO TERRITORIAL DE VIADUTOS/RS E DA LINHA ALDA.}

O Distrito de Viadutos assim como todo o Alto Uruguai, segundo Giaretta (2008, p.20), foi colonizado pela empresa Luce \& Rosa, criada em 1883, a qual possuía sede em Porto Alegre e uma filial em Barro (atual município de Gaurama). Os sócios da empresa possuíam 3.641 colônias de terras nesta região.

O processo de colonização no Alto Uruguai foi deflagrado com a inserção desta empresa colonizadora agregada a outras duas empresas colonizadoras: Jewisch Colonization Association (ICA), e a Sociedade Territorial Eberle, Mosele, Ahrons \& Cia (CHIAPARINI, 2012, p. 50). Esta última teria colonizado a região que compreende Marcelino Ramos e Viadutos a partir de 1920. Destaca-se, a chegada de mais um grupo de imigrantes na Linha Alda, totalizando 17 famílias até 1940.

Um dos moradores (91 anos) relatou que nas primeiras décadas do século passado (1909 1920), a primeira atividade econômica consistia na extração de madeira e venda para a Região Sudeste do Brasil e para a Argentina. Outra parte foi utilizada na construção da ferrovia, que ligou o estado do Rio Grande do Sul até São Paulo, as atividades econômicas passaram a ser as lavouras de milho, cana-de-açúcar, arroz, feijão, trigo, erva mate, bem como para a pecuária, com enfoque para a criação de suínos, segundo relatos dos moradores e registrado em Ducatti (1981, p.358). Estes espaços, atualmente (2019), são utilizados basicamente para a produção de commodities: soja e milho.

A dinâmica econômica e social do distrito de Viadutos, nos primeiros anos de colonização (1920 - 1940), pode ser observada, segundo Chiaparini (2012, p.114), por meio da variedade de serviços disponibilizados em todos os distritos do então município de Erechim, incluindo Viadutos. 
Um dos moradores (91 anos) recordou que a produtividade da unidade familiar compreendia a produção de grãos (feijão, trigo e milho), legumes e vegetais, como batatas, mandioca, amendoim, cebola, bem como, a criação de suínos tanto para o consumo da família como para venda de excedentes que geralmente ocorriam no moinho da família Zordan ou no comércio de Alfonso Alberto Von Mühlen e Ernesto Veronese, localizados na sede do distrito de Viadutos, e referenciados em Chiaparini (2012, p.115).

A produção agrícola no Alto Uruguai, segundo Piran (2001, p.31) caracterizou-se em duas fases. A primeira fase, denominada tradicional, iniciando no período da colonização no início do século XX e a segunda fase identificada como moderna, delimitada a partir dos anos 1980. Esse autor destaca que na agricultura tradicional, os agricultores familiares produzem quase tudo que necessitam na propriedade, ou seja, as famílias trabalhavam no modo de subsistência familiar, só comercializando o excedente.

Nesta perspectiva, a fala do agricultor (91 anos) enfatiza e confirma o estudo de Piran (2001), em relação a produção e venda de excedentes da produção agrícola pelas famílias. Segundo a fala deste morador, transportava-se o excedente da produção familiar até a sede do distrito por meio de cavalos e carroças. Em alguns casos e conforme a quantidade de excedentes produzidos, os comerciantes realizavam a coleta da produção (milho, feijão, trigo) com um "par de mulas”, o pagamento da produção vendida realizava-se após descontar o frete do transporte.

As unidades familiares são características do modelo agrícola baseado na agricultura familiar. Segundo a Lei Nacional, $\mathrm{N}^{\mathrm{o}} 11.326$ de Julho de 2006, em seu artigo $3^{\circ}$, entende-se enquanto agricultor familiar, aquele que executa atividades no meio rural em que a porção de terras não seja maior que 4 (quatro) módulos fiscais. Destaca no inciso III, que a renda familiar deve ser “originada de atividades econômicas do seu estabelecimento ou empreendimento, na forma definida pelo Poder Executivo; (Redação dada pela Lei n 12.512, de 2011)”, assim como, no inciso IV, a propriedade deve ser dirigida pelo agricultor e sua família.

Nesta lógica, Neves (2012, p.35) refere-se à agricultura familiar como um conjunto de diversidades e situações históricas e socioeconômicas, que "correspondem a formas de organização da produção em que a família é ao mesmo tempo proprietária dos meios de produção e executora das atividades produtivas".

Neste tocante, entendendo a agricultura familiar enquanto um conjunto de formas e situações que compreende uma relação interna em que os proprietários são também os produtores das atividades agrícolas, um dos agricultores (91 anos) destacou que a adubação da terra era 
realizada por meio da coivara ${ }^{4}$, quando notava-se que a "terra enfraquecia" e a produtividade reduzia, uma parcela da área produtiva era inutilizada por 3 ou 4 anos para que a vegetação crescesse e a matéria orgânica decorrente da queimada se transformasse em adubo.

A técnica da Coivara é considerada desde 2018 segundo Iphan, patrimônio cultural ${ }^{5}$ dos quilombolas, e embora os agricultores não tenham expressado em suas falas a presença ou influência de povos tradicionais, o uso de técnicas como a coivara demonstra a presença destes povos no Alto Uruguai. Nota-se a apropriação destes saberes por parte dos agricultores da localidade entre o início da ocupação destas áreas, 1909 -1950.

O plantio e a colheita dos cereais, segundo um dos agricultores (91 anos), realizavam-se manualmente com ajuda de toda a família incluindo as mulheres e os filhos, e algumas vezes ocorria a troca de serviço entre os vizinhos. Justificando, deste modo, as características das famílias, serem numerosas.

Neste sentido, Ploeg (2016, p.31) destaca que,

[...] dentro da economia camponesa, o trabalho é em grande parte viabilizado pela família.[...]. O 'capital', contido na propriedade camponesa consiste na casa e outras instalações, a terra, as diversas melhorias empregadas nela(...), os animais, o material genético disponível, o maquinário,(...). A memória também é uma parte intrínseca desse capital (PLOEG, 2016, p. 31).

Sendo a unidade familiar, o próprio capital na perspectiva da economia camponesa, este fator trouxe algumas implicações para as primeiras famílias de emigrantes, como se observou na fala de uma das moradoras (87 anos). Esta destacou que inicialmente as unidades rurais, que hoje (2019) pertencem a uma única família, eram divididas entre duas ou mais famílias, o que correspondia a uma média de 15 a 20 pessoas vivendo sobre uma porção de terras, tornando-se assim um espaço reduzido para a produção agrícola. Deste modo, o capital da economia camponesa tornava-se ainda mais escasso. Este tamanho das unidades familiares é uma característica do período de colonização do Estado do Rio Grande do Sul a partir da metade do século XIX.

A colonização do Rio Grande do Sul, iniciada na segunda metade do século XIX, baseavase numa estrutura de pequenas propriedades rurais [...]. A partir de 1889, com a intensificação da imigração para a frente colonial, e o consequente aumento da demanda de terras livres, a área média das propriedades baixou para 25 ha.[...]. Como a terra era obtida através de compra, segundo a exigência da Lei de Terras de 1850, o colono, ao instalar-se já estava endividado, e por isso mesmo, ansioso por saldar rapidamente sua

\footnotetext{
4 Coivara, segundo o geógrafo Leo Waibel (1949), representa uma técnica indígena, também conhecida como sistema de corte e queimadas. Informações disponíveis em: WAIBEL.L. Princípios da Colonização Européia no Sul do Brasil. Revista Brasileira de Geografia. Ano XI. n. 2. p.159-217. 1949.

${ }^{5}$ Os quilombolas desenvolveram há mais de 300 anos um cultivo de alimentos na Mata Atlântica que não usa adubo nem agrotóxico, chamada roça de coivara. informações coletadas no site Agência Brasil.
} 
dívida. Seu primeiro impulso era, portanto, o de produzir excedentes comercializáveis. (FERES, 1990, p. 496)

O processo de colonização, envolvendo as famílias residentes na Linha Alda, implicou na necessidade de algumas destas famílias imigrarem novamente. Feres (1990) destaca, que o tamanho das propriedades a partir do final do século XIX, correspondia a 25 hectares. Entretanto, em relato dos agricultores mais velhos da Linha Alda, a porção de terras, que 9 famílias entre 1909 e 1920 receberam foi de 2 colônias o equivalente a 50 hectares, ou seja, uma porção territorial relativamente reduzida, se comparada ao padrão definido pelas empresas colonizadoras de 25 hectares por família. Além disso, esta porção de terras foi subdividida entre as primeiras 9 famílias que chegaram na localidade.

As famílias que emigraram da linha Alda acabaram fazendo parte de um plano do Governo Federal, no qual o então presidente Getúlio Vargas colocou em prática a política de expansão territorial, pontuado por Feres (1990),

[...]desde 1924 pelos tenentes, de ocupação da fronteira sul, na região de Foz do Iguaçu, Getúlio Vargas lançou seu plano de colonização dirigida. O Estado aplicando o costume de facilitar os investimentos privados, passou a fazer doações de terras devolutas, mediante venda simbólica.[...]. Criava-se, para isso, em 1943, no então Território Federal de Iguaçu, a Colônia Agrícola Nacional General Osório (CANGO),[...]. (FERES, 1990, p.498)

Buscando melhores condições de vida e também propriedades agrícolas maiores, que pudessem de fato trazer o retorno financeiro esperado entre os anos de 1930-1940, seis famílias emigraram para os Estados de Santa Catarina e Paraná. Tinham o objetivo de trabalhar com a produção de café e adquirir suas propriedades rurais, para tal decisão, as famílias foram influenciadas por notícias sobre a garantia de compra de terras a preços acessíveis no Paraná.

Nesta perspectiva, Sack (2001) define a territorialidade enquanto "ferramenta estratégica" de um grupo de pessoas sobre outras em diferentes territórios, atuando sobre as relações sociais e pode ser observada quando expressa sua utilidade,

[...] a territorialidade para humanos é uma poderosa estratégia geográfica para controlar pessoas e coisas através do controle da área. [...] a territorialidade é utilizada em relacionamentos cotidianos e em organizações complexas. Territorialidade é uma expressão geográfica primária de poder social. É o meio pelo qual espaço e sociedade estão inter-relacionados. (SACK, 2001, p.63)

O conceito de territorialidade pode ser utilizado para analisar a fala de uma das moradoras (85 anos), quando relata as experiências do vivido na localidade desde 1920. 
[...]naquela época não era hoje, plantavam soja no meio do milho, colhiam tudo a mão, plantavam e colhiam o trigo a mão, limpavam a lavoura com enxada, cada um tinha seus porcos, suas galinhas, a maioria das famílias plantava feijão para o gasto, arroz para o gasto, vaca de leite para o gasto ${ }^{6}$ e milho, o pouco que sobrava da produção se vendia na loja, se sobrava um pouco de trigo carregava um saco a cavalo se levava até a loja “comércio Birck e Cia Ltda”, na Linha Três, para fazer farinha.

A dinâmica demográfica e territorial foram fundamentais para que o grupo familiar conseguisse se reproduzir social e economicamente: faziam as casas, as roupas, produziam a maioria dos alimentos. Além disso, havia dinâmicas de reciprocidades comunitárias, em função de que, a prioridade estava em viabilizar a fixação e o pagamento da terra para as companhias de colonização ou para o Estado.

As territorialidades são permeadas e caracterizadas por "continuidades e descontinuidades no tempo e espaço, as territorialidades estão intimamente ligadas a cada lugar: elas dão lhe identidade e são influenciadas pelas condições históricas e geográficas de cada lugar" (SAQUET, 2008. p.88)

As primeiras 9 famílias a chegar no território da Linha Alda (oriundas de Nova Roma, distrito de Antônio Prado/RS, atualmente município de Nova Roma do Sul/RS) trouxeram suas identidades e territorialidades transpuseram seus costumes religiosos e vínculos sociais entre os vizinhos em um novo espaço, porém reproduzindo um modo de viver já apreendido no antigo lugar que residiam.

A construção da identidade social das famílias de agricultores da Linha Alda ocorreu por meio das crenças religiosas, destaque para a católica por volta de 1930 iniciou o movimento de construção da sede da comunidade, denominada Comunidade da Capela São José. A sede comunitária católica, institucionalizada em 1939 pela paróquia de Santa Maria/RS, concentrava pessoas de localidades próximas, oriundas da Linha Três e Linha Barbará que se deslocavam semanalmente para os cultos e missas católicas, segundo relato de um dos moradores (89 anos).

\footnotetext{
${ }^{6}$ Produção para o autoconsumo da família, sem comercialização de excedentes.
} 


\section{AS DINÂMICAS SOCIAIS DA LINHA ALDA: A modernização dos meios produtivos na agricultura} familiar.

Entre 1980 - 1990 aproximadamente 13 famílias viviam na localidade da Linha Alda. O total de moradores deste período, segundo relato de um dos agricultores (63 anos), era de aproximadamente 55 pessoas.

A medida que os jovens atingiam a idade entre os 16 - 18 anos saiam do campo por falta de perspectivas em relação a melhorias nas condições de vida. As dinâmicas territoriais da Linha Alda são expressões da dominação do modelo econômico vigente sobre as tomadas de decisões dos agricultores(as) e familiares. Neste tocante, Oliveira (2012) enfatiza que,

[...] A monopolização do território é desenvolvida pelas empresas de comercialização e/ou processamento industrial da produção agropecuária, que sem produzir no campo, controlam através de mecanismos de subordinação, camponeses e capitalistas produtores do campo. [...] No Brasil, monopolizam o setor de grãos, as empresas mundiais ADM, Cargil, Bunge, LDC; Los Grobos, El Tejar e Enrique Bañuelos; as nacionais Caramuru e AMAGGI que está indo para a Argentina; e, as cooperativas Coamo e Cocamar. No setor de sementes atuam a Monsanto e a Syngenta.(OLIVEIRA, 2012, p.10)

Dentre as consequências da monopolização do território pelo capital, destaca-se a atuação das empresas comercializadoras, citadas por Oliveira (2012), que meticulosamente repassavam os seus prejuízos financeiros para os agricultores familiares na forma de redução do preço pago na venda dos cereais e no aumento dos custos para o plantio. Nota-se que a modernização não se baseou em políticas e tecnologias apropriadas ao contexto da agricultura familiar. Isso pode ser observado, em função das novas técnicas empregadas principalmente em relação a produção agrícola, "a tal ponto que as tarefas antes de responsabilidade de toda a família passaram a ter caráter mais individualizado", como expressou José Graziano da Silva (p. 165).

O capital, na agricultura familiar caracteriza-se como invisível, "onde não se consegue realizar o lucro médio nem tampouco a renda da terra", (Amin e Vergopoulos, 1982). As crises financeiras relatadas pelos agricultores, intensificadas a partir de 1990 e que se estenderam até aproximadamente o ano de 2005, expressam a estagnação do(a) agricultor(a) familiar. Afinal a estagnação era baseada na produção de commodities (milho, soja, trigo), leite e a criação de suínos no modelo de integração com empresas e cooperativas.

As territorialidades expressas sobre a Linha Alda podem ser divididas em dois tipos. Dematteis (2008, p.35) tipifica as territorialidades em passiva e ativa, a primeira tem estratégias de controle e objetiva excluir sujeitos e recursos, enquanto que a territorialidade ativa, tem por objetivo ações coletivas territorializadas e territorializantes e visa construir estratégias de inclusão. 
A produção de territorialidades passivas por parte das empresas de comercialização sobre as unidades familiares acabou se homogeneizando com a produção de commodities, especialmente através da produção de soja e milho. Fato comprovado a partir da fala de um dos moradores (56 anos), quando citou o slogan do governo Federal de 1970: "Soja: Plante que o Governo garante". Nota-se que as empresas de comercialização sabem trabalhar com a vulnerabilidade dos sujeitos do campo.

Nesta acepção, Ploeg (2016), aponta que,

O Estado é uma entidade que reflete e governa - direta e indiretamente - as relações entre as economias urbana e rural e, portanto, as relações entre mercados e produtores primários, a natureza da migração e as inter-relações entre camponeses, comerciantes e processadores de alimentos. Mas é mais do que isso. O Estado também é uma força autônoma que impõe sua própria marca na dinâmica rural. (PLOEG, 2016, p. 103)

A propaganda expressa a interferência de um agente externo, neste caso o Estado e as empresas comercializadoras dos pacotes da revolução verde, sobre as decisões dos(as) agricultores(as), quanto a adesão aos pacotes tecnológicos. Os agricultores investiram na compra das sementes, que até então eram produzidas e guardadas no núcleo familiar. Este ideal, induzido através de políticas federais, implicou na falsa ideia de que este novo modelo produtivo que incentiva o mono cultivo e a redução de variedades, traria maior retorno financeiro.

A territorialidade, da qual aborda Sack (2001), enquanto estratégia geográfica de controle de pessoas a partir do controle de áreas, expressa a territorialidade das empresas sobre as propriedades rurais. E a vida dos(as) agricultores(as) familiares pode ser observada, a partir da oferta de trabalho vinculada ao uso do espaço da propriedade rural para criação de suínos ou produção de leite, denominada como integração entre a empresa e o agricultor. 


\section{Fotografia 1- Espaço para criação de suínos construído em 1987.}

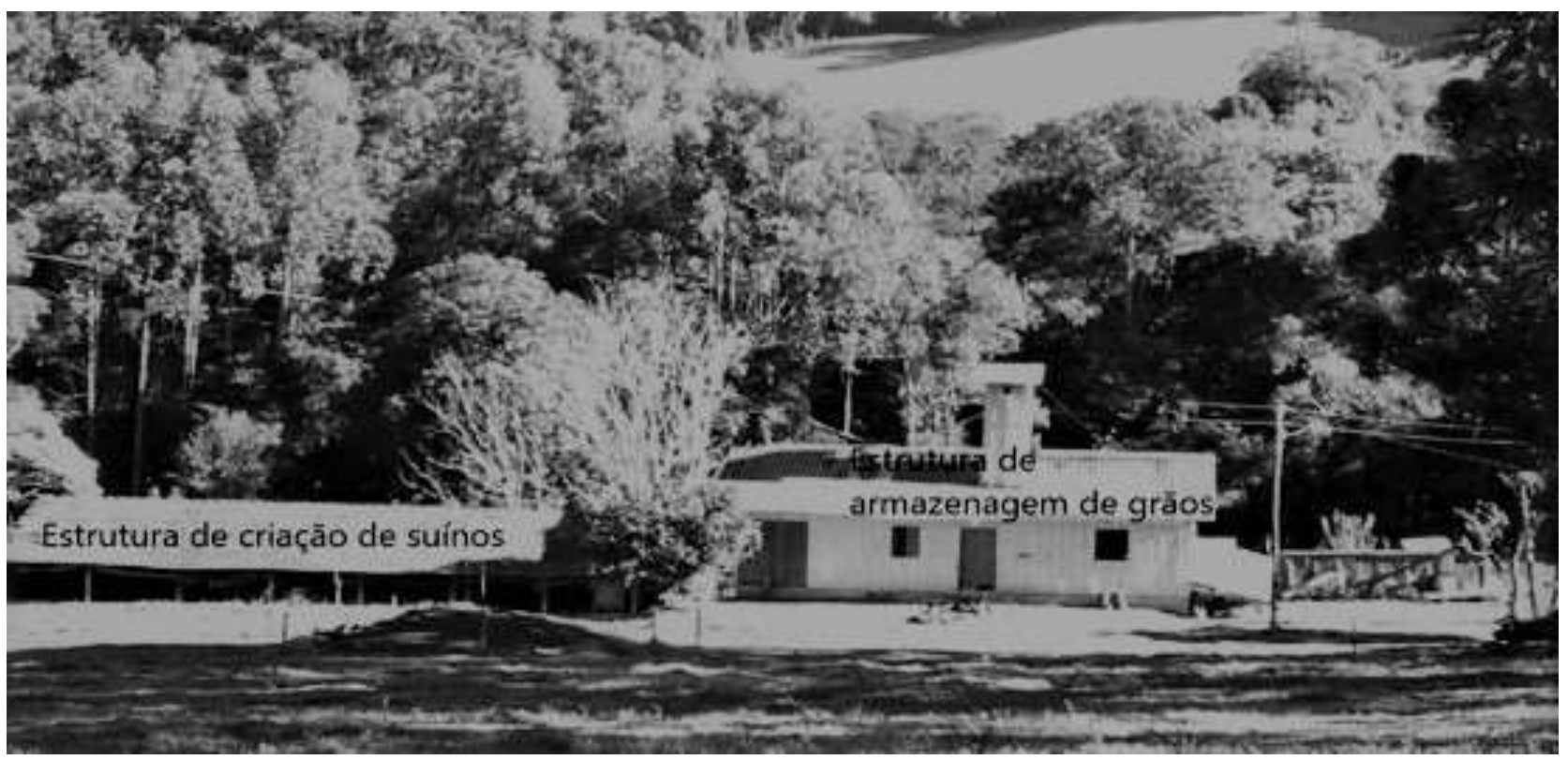

Fonte: Fagundes, 2013(Org. Fagundes, 2019).

Os(as) agricultores(as) acabaram perdendo sua autonomia e identidade de agricultores(as) familiares e passaram a reproduzir a lógica produtiva das empresas, sem dimensionar quais os custos e os esforços realizados para garantir a produção e os investimentos feitos, como a construção de estruturas físicas para a criação dos suínos, a produção de leite e a produção de grãos (milho, soja e trigo).

Rafestin (1993, p.160) destaca que “a vida é tecida por relações”. Neste sentido, a territorialidade pode ser entendida como "um conjunto de relações que se originam num sistema tridimensional sociedade-espaço-tempo", buscando "a maior autonomia possível, compatível com os recursos do sistema".

A face vivida da territorialidade é expressa através do desejo dos agricultores em acompanhar os avanços tecnológicos e as exigências das empresas comercializadoras dos pacotes de produção, que visavam o lucro empresarial, a partir da produção com custos reduzidos expressos na forma como as "parcerias" estabeleciam-se.

Os agricultores destinavam um espaço das propriedades para construção das estruturas físicas, arcavam com os custos de água, luz, mão de obra e tempo. Enquanto as empresas responsabilizavam-se em entregar e "comprar" os suínos e a produção de leite dos agricultores. Nessa lógica, os agricultores acabaram fazendo investimentos altos em suas propriedades para atender a uma demanda empresarial, que não condizia com a realidade do espaço rural que viviam. 
Na fotografia 1 observa-se o reduzido tamanho das estruturas construídas para a criação de suínos na época (1987), aproximadamente 20 metros de comprimento, com capacidade para 140 suínos, segundo informações de um dos agricultores (64 anos).

As empresas integradoras exigiam a padronização dos espaços de criação de suínos, entretanto, no final da década de 1990, os agricultores não conseguiram acompanhar as exigências das empresas, tendo em vista, que o valor pago pela criação de suínos não condizia com os esforços e investimentos realizados na unidade familiar. Foi neste período que as "parcerias" com as empresas PERDIGÃO ${ }^{7}$ e SADIA $^{8}$, começaram a ser desfeitas, entretanto as dívidas contraídas na construção dos primeiros espaços de criação de suínos ainda não haviam sido quitadas.

Os jovens agricultores, que permanecem nas propriedades familiares (2019), parecem não ver alternativas para mudar o modelo de produção agrícola baseado na produção de grãos, que é o foco produtivo atualmente.

Desde 2010, as famílias deixaram de trabalhar com a produção de leite e criação de suínos, no modelo de integração com as cooperativas citadas, em função da desvalorização do produto, que encarecia a produção e das exigências de modernização impostas pelas empresas integradoras, dentre as quais, pode-se citar a COOPERAL ${ }^{9}$, a COTREL ${ }^{10}$ e a AURORA ${ }^{11}$. Cabe ressaltar que apenas uma família da Linha Alda mantém a produção de suínos para o beneficiamento e comercialização dos subprodutos (banha, salame e carne), no município de Viadutos, realizada na Agroindústria e Frigorifico da Família Munaro. ${ }^{12}$

Neste sentido, Ploeg (2016, p.131-2) destaca que a "agricultura camponesa regride quando novas tecnologias de alto capital são empregadas em empreendimentos agrícolas de grande escala". Estes empreendimentos superam a capacidade produtiva das unidades familiares, afastando-as do mercado.

\footnotetext{
${ }^{7}$ PERDIGÃO empresa criada em 1930 em Videira/SC. Duas famílias de descendentes italianos, Brandalise e Ponzoni decidem criar um comércio de secos e molhados que mais tarde transforma-se na então Perdigão. Mais informações em:https://www.trabalhosfeitos.com/ensaios/Hist\%C3\%B3ria-Da-Perdig\%C3\%A3o/56870919.html . Acesso em nov. 2019.

${ }^{8}$ Em 1930 Atílio Fontana, criava a SADIA, em Concórdia/SC a partir de um moinho de trigo e comercialização de suínos para empresas locais. Dados extraídos do site: https://www.aviculturaindustrial.com.br/imprensa/sadia-comemora-70-anos-dehistoria/20140609-083115-u710. Acesso em: nov. 2019.

${ }^{9}$ COOPERAL - Cooperativa dos produtores rurais. Sede em Erechim/RS.

${ }^{10}$ COTREL - Cooperativa tritícola de Erechim. Sede em Erechim/RS, esta cooperativa teve suas atividades encerradas no ano de 2018, após decretar falência.

${ }^{11}$ AURORA- Cooperativa Central Aurora Alimentos -compreende um sistema de 11 cooperativas filiadas em sistema de cooperação regional que compreende o oeste catarinense, criada em 1969.

${ }^{12}$ Agroindústria e Frigorifico da Família Munaro, criada em 2015, a agroindústria trabalha em regime familiar envolvendo 4 pessoas da família e abate além de suínos, bovinos e ovinos, realizando o processamento de carnes e subprodutos dos mesmos.
} 
Segundo Silva (1998, p.30) a modernização da agricultura é um processo genérico representado pela integração da agricultura no sistema capitalista industrial, principalmente por meio das alterações tecnológicas e de ruptura das relações de produção arcaicas e do domínio do capital comercial. Esse processo acaba se acentuando após a década de 1960.

Observa-se que o moderno, ao qual se refere Silva (1998), chegou parcialmente na localidade da Linha Alda, apenas em relação à produção agrícola. Em outras dimensões da vida, como a educação, a comunicação e a circulação não ocorreram, a modernização.

\section{E AGORA, CHEGAMOS AO FIM DA LINHA?}

No passado a relação do agricultor familiar com a produção agrícola era delimitada pelo viver no espaço rural e reproduzir os ensinamentos passados de geração em geração nas famílias. Viver no campo era seguir uma rotina referente ao cuidado com os animais e uma carga horária triplicada nos períodos de colheita e plantio das lavouras. Diferente de um emprego no espaço urbano, que compreende geralmente 8 horas diárias, 5 ou 6 vezes por semana.

Para não concluir, mas instigar futuras pesquisas sobre o espaço rural e as transformações nas dinâmicas territoriais da agricultura familiar no século XXI, alguns elementos podem ser apresentados a partir da atual configuração produtiva das propriedades rurais. Um deles está na saída destes últimos agricultores e suas famílias do espaço rural, a medida em que a idade dos mesmos for aumentando.

Matte, Spanevello, Lago e Andreatta (2019, p.26) destacam que dentre alguns fatores estruturais do meio rural, a necessidade de lazer é pertinente, o qual está associado à proximidade do urbano, além do acesso a comunicação, como o acesso à internet. "A limitação ao acesso da internet para quem mora no meio rural, segundo os filhos de pecuaristas entrevistados, é bastante presente."

O acesso à internet pode ser uma ferramenta para a permanência dos jovens da Linha Alda permanecerem no espaço rural, uma vez que a falta de espaços de lazer na comunidade, restringe o convívio social dos jovens (12 a 20 anos), basicamente ao espaço familiar e ao ambiente escolar, para dois dos três jovens, que ainda se encontram em idade escolar. O espaço de convívio social, representado pelo bar comunitário, localizado junto à sede comunitária São José, é frequentado expressamente por homens, com exceção dos eventos anuais, em que grupos de jogadores mistos de bocha frequentam o local para disputar os "campeonatos de bocha". 
As famílias que permanecem no espaço rural, compreendem um total populacional de 20 pessoas (Quadro 1). Destas, a maioria encontra-se em faixas etárias acima dos 50 anos de idade, o que caracteriza um público majoritariamente idoso. Esta lacuna é um reflexo de um momento de crise econômica dos(as) agricultores(as) familiares, que buscaram adequar-se ao modelo produtivo baseado em commodities.

Quadro 1- Quantitativo populacional e de faixas etárias dos moradores - Linha Alda 2019.

\begin{tabular}{|c|c|c|c|}
\hline Idades & Homens & Mulheres & Total \\
\hline $10-25$ & 2 & 1 & 3 \\
\hline $26-40$ & 0 & 0 & 0 \\
\hline $41-55$ & 0 & 1 & 1 \\
\hline $56-70$ & 5 & 5 & 10 \\
\hline $71-85$ & 0 & 3 & 4 \\
\hline Total & 2 & 1 & 20 \\
\hline
\end{tabular}

Fonte: Org. AUTORES, 2019.

Hoje, não é mais expressiva a produção para o autossustento, nos contextos de territórios monopolizados pela produção de grãos, não faz mais sentido o modo de vida rural. O campo tornase assim, apenas um espaço de produção convencional, (soja, milho, trigo), que transforma o modo de vida dos agricultores em um desafio cotidiano.

Enquanto pesquisadora, e ex. jovem agricultora da localidade da Linha Alda, evidencia-se um ideal de vida, expresso no êxodo rural, o qual, na localidade deu-se em função da busca por melhores condições de vida, ou o que Chayanov (O campesinato, 2014), destacou sobre o campesinato, em que a migração para a cidade compreendia desde um emprego assalariado, visando a "segurança" financeira no futuro (lembrança dos períodos de crise econômica na família), a oportunidade de estudar, e ter uma vida "tranquila" (sem crises financeiras, sem miséria na mesa, sem condições precárias de moradia, educação e lazer).

Fazendo uma retrospectiva social das famílias da localidade, observou-se que quatro gerações existiram e resistem ao longo deste um século e quase três décadas sobre a localidade da Linha Alda. Essas quatro gerações de agricultores(as) familiares passaram por processos de adaptação a uma nova localidade, acreditaram em propostas de melhorar as condições econômicas da família, aderiram a pacotes tecnológicos, esperançosos de um novo rumo para suas vidas e atualmente, poucas famílias resistem no espaço rural.

Destaca-se que nunca houve uma política de convergência com o modo de vida da agricultura familiar e nota-se que sempre existiu um movimento de adaptação e dependência. 
Neste sentido, observa-se um desperdício de recursos cognitivos e ambientais para estimular a produção primária e de baixo valor agregado, que poderia ser transformado em outras formas de trabalho no rural, por exemplo o trabalho com sistemas agroflorestais - SAFS.

\section{CONSIDERAÇÕES FINAIS}

Neste sentido, conclui-se que a produção convencional agrícola que começou a ser reproduzida através de mecanismos do final do século XX, (tratores, colheitadeiras e plantadeiras), combinado ao reduzido espaço da propriedade rural, a falta de apoio dos pais e de políticas públicas municipais que incentivassem os jovens a permanecerem no campo são fatores que interferem diretamente no reduzido número de pessoas jovens ou abaixo dos 50 anos vivendo sobre a localidade da Linha Alda atualmente.

Os agricultores situados na Linha Alda passaram por diferentes períodos econômicos expressos nas transformações das dinâmicas territoriais. Em aproximadamente um século (1910 2019). Deste modo, através da observação e compreensão das dinâmicas territoriais foi possível perceber que os vínculos sociais das famílias pertencentes à Linha Alda, encontram-se difusos. A maioria das pessoas, que permanecem residindo na localidade encontra-se na faixa etária entre 55 65 anos, demonstrando assim que a população da Linha Alda se constitui majoritariamente por idosos.

Neste sentido, ousamos dizer que as perspectivas sobre a configuração social da localidade não são promissoras. Sugere-se que sejam realizados investimentos em políticas públicas municipais, que de fato contemplem e favoreçam a vida dos agricultores familiares que buscam permanecer no espaço rural.

Apesar de existirem movimentos para que os jovens permaneçam no campo, deve-se pensar quais são as alternativas propostas e quais as opções dadas para que os jovens retornem ou decidam viver com base no trabalho rural. Uma das possibilidades é fomentar outros tipos de relação com a terra, por exemplo a produção agroecológica e orgânica de hortaliças e grãos, pensando em abastecer inicialmente um mercado consumidor local e fortalecer os laços com um mercado consumidor regional já existente sobre a região geográfica imediata de Erechim/RS. Nesta perspectiva, pode-se investir em modos de cultivos alternativos, que fortaleçam os vínculos sociais, fomentando. A produção agroecológica, ou a implantação de Sistemas Agroflorestais - 
SAFS, entre outras possibilidades, que possam de fato trazer incentivos àqueles que ainda desejam permanecer no campo.

\section{REFERÊNCIAS}

BRASIL. LEI NACIONAL No11.326. Brasília, DF. 2006. Disponível em: <http://www.planalto.gov.br/ccivil_03/_Ato20042006/2006/Lei/L11326.htm\#targetText=LEI\%20N\%C2\%BA\%2011.326\%2C\%20DE\%2024\%20D E\%20JULHO\%20DE\%202006.\&targetText=Estabelece\%20as\%20diretrizes\%20para\%20a,Famili ar\%20e\%20Empreendimentos\%20Familiares\%20Rurais.> Acesso em: 2 de out. de 2019.

CHIAPARINI, Enori José. Erechim: Retratos do passado, memórias do presente. Erechim, Graffoluz, 2012, p. 50 - 120.

DEMATTEIS, Giuseppe. Sistema Local Territorial (SLOT): Um instrumento para representar, ler e transformar o território. In: ALVES, F. Adilson et al. (Org) Desenvolvimento Territorial e Agroecologia. GETER, Expressão Popular. 2008, p. 33-46.

DUCATTI, N. Antonio. Gaurama. In DUCATTI, N. Antonio. O Grande Erechim e sua história. 1.ed. Porto Alegre, 1981, p. 358.

FERES, B. João. Propriedade da terra: Opressão e Miséria. O meio rural na história social do Brasil. Amsterdan, CEDLA. (dissertação), orientador: J.M.G.Kleinpeiming. Universidade de Nijmegen, 1990, p. 681.

GIARETTA, S. G. Jane. Aspectos da dinâmica socioeconômica da colônia Erechim. In: GIARETTA, S. G. Jane. O Grande e velho Erechim: ocupação e colonização do povoado de Formigas (1908-1960). Passo Fundo, UPF (Dissertação), 2008, p.31 - 62.

GIL, C. Antonio. Métodos e técnicas de Pesquisa Social. 2. ed. São Paulo, Atlas, 1987, p.44.

INSTITUTO BRASILEIRO DE GEOGRAFIA E ESTATISTICAS. Cidades. Disponível em: <https://cidades.ibge.gov.br/brasil/rs/viadutos/panorama > Acesso em: 10 Mar, 2020..

INSTITUTO BRASILEIRO DE GEOGRAFIA E ESTATISTICAS. Censo agropecuário. Disponível em: $<$ https://cidades.ibge.gov.br/brasil/rs/viadutos/pesquisa/24/0> Acesso em 15 de set. 2018.

INSTITUTO BRASILEIRO DE GEOGRAFIA E ESTATÍSTICAS. Histórico do município. Disponível em: <https://cidades.ibge.gov.br/brasil/rs/viadutos/historico> Acesso em: 01 out. 2019.

LAKATOS E. Maria; MARCONI A. Marina de. Técnicas de pesquisa. In: LAKATOS E. Maria; MARCONI A. Marina de. Fundamentos de metodologia científica. 7 ed. São Paulo, Atlas, 2010.

MATTE Alessandra; SPANEVELLO M. Rosani; LAGO Adriano; ANDREATTA Tanice. Agricultura e pecuária familiar: (Des) continuidade na reprodução social e na gestão dos negócios. Revista Brasileira de Gestão e Desenvolvimento Regional. G\&DR, Taubaté, 2019, v. 15, a.1, p. 19-33. 
NEVES, P. Delma. Agricultura familiar In: CALDART, S. Roseli; PEREIRA, B. Isabel; ALENTEJANO, Paulo; FRIGOTTO Gaudêncio (Org.). Dicionário da Educação do Campo. Rio de Janeiro, Expressão Popular, 2012. p.32 - 39.

OLIVEIRA, U. Ariovaldo. A Mundialização da agricultura brasileira. In: XII COLÓQUIO INTERNACIONAL DE GEOCRITÍCA. Geocritica. Bogotá, 2012, p. 10 -15.

PIRAN, Nedio. As Fases da Agricultura no Alto Uruguai. In: PIRAN, Nedio. Agricultura familiar: Lutas e perspectivas no Alto Uruguai. Erechim, EDIFAPES, 2001, p. 31

PLOEG, Jan Douwe van der. Camponeses e a arte da agricultura: um manifesto

Chayanoviano. Porto Alegre, Editora UFRGS, 2016, v. 1, p, 181.

RAFFESTIN, Claude. O Território e o poder. In: Pour une géographie du pouvoir. Tradução de Maria C. Français. São Paulo. Ática, 1993, p. 143-163.

SACK, D. Robert. O significado de territorialidade. In: DIAS, L. Christina; FERRARI, Maristela. (Org.) Territorialidades Humanas e Redes Sociais. 1.ed. Florianópolis, INSULAR, 2011, p.63 90 .

SAQUET, A. Marcos. Por uma abordagem territorial. In: SAQUET, A. Marcos; SPOSITO, S. Eliseu (Org.). Territórios e territorialidades: teorias, processos e conflitos. 1.ed. São Paulo, Expressão Popular, 2008, p. 73 - 88.

SILVA G. José da. Do complexo rural aos complexos agroindustriais. In: SILVA G. José da. A nova dinâmica da agricultura brasileira. São Paulo, UNICAMP, v.2 1998.

WAIBEL, L. H. As zonas pioneiras do Brasil. Revista brasileira de geografia, n. 4, out./dez., 1955. 